\title{
Heart Failure in Patients with Diabetes and Chronic Kidney Disease: Challenges and Opportunities
}

\author{
Kris Vijay $^{a}$ Brendon L. Neuen ${ }^{b}$ Edgar V. Lermac, ${ }^{c}$

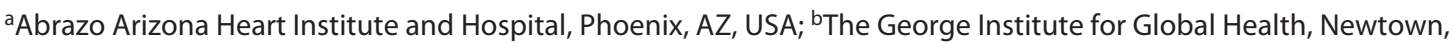 \\ NSW, Australia; ' University of Illinois at Chicago College of Medicine, Chicago, IL, USA; ${ }^{d}$ Advocate Christ Medical \\ Center, Oak Lawn, IL, USA
}

\section{Keywords}

Heart failure · Comorbidity · Diabetes mellitus · Chronic

kidney disease

\section{Abstract}

Background: Heart failure (HF), diabetes mellitus (DM), and chronic kidney disease (CKD) are commonly occurring and interlinked conditions. Approximately $25 \%-40 \%$ of patients with $\mathrm{HF}$ have DM, and approximately $40 \%-50 \%$ of patients with HF have CKD. Both DM and CKD are associated with increased risk of incident HF. Furthermore, $40 \%$ of people with DM develop CKD, making DM the leading cause of kidney failure globally. Importantly, $16 \%$ of patients with HF have both comorbid DM and CKD, and the combination of these 3 comorbidities is associated with substantially increased risk for hospitalization and mortality. Mechanisms that underlie the relationships between HF, DM, and CKD are complex but likely relate to shared cardiovascular and metabolic risk factors, as well as downstream effects on inflammation, oxidative stress, and neurohormonal pathways. Summary: This review outlines the epidemiology and links between HF, $D M$, and CKD, as well as current clinical evidence for the treatment of individuals with a combination of these comor- bidities. A case study of a patient with concomitant HF, DM, and CKD is discussed to explore potential treatment approaches for patients in whom all 3 comorbidities exist. Key Messages: Treatment plans for patients with a combination of these 3 comorbidities should consider the available clinical evidence.

(c) 2021 The Author(s)

Published by S. Karger AG, Basel

\section{Introduction}

Heart failure (HF) is a major global health issue that commonly occurs in the presence of diabetes mellitus (DM) and chronic kidney disease (CKD) (Fig. 1). Considering the prevalence of each individual condition, the Global Burden of Disease Study 2017 reported that approximately 64 million people had HF, 476 million had DM, and 698 million had CKD [1]. DM occurs in $40 \%$ of patients with acute $\mathrm{HF}$ and $25 \%$ of patients with chronic HF [2], while CKD occurs in $53 \%$ of patients with acute HF, $42 \%$ of patients with chronic HF [3], and $40 \%$ of patients with DM (Fig. 1) [4]. Importantly, 16\% of patients with $\mathrm{HF}$ have comorbid DM and CKD, with the resulting

Correspondence to:

karger@karger.com www.karger.com/crm

Karger $\stackrel{\text { ' }}{5}$
C) 2021 The Author(s).

Published by S. Karger AG, Basel

This is an Open Access article licensed under the Creative Common Attribution-NonCommercial-4.0 International License (CC BY-NC) (http://www.karger.com/Services/OpenAccessLicense), applicable to the online version of the article only. Usage and distribution for commercial purposes requires written permission. 
Fig. 1. Complex interplay among HF, DM, and CKD and common factors associated with their development [1-6].

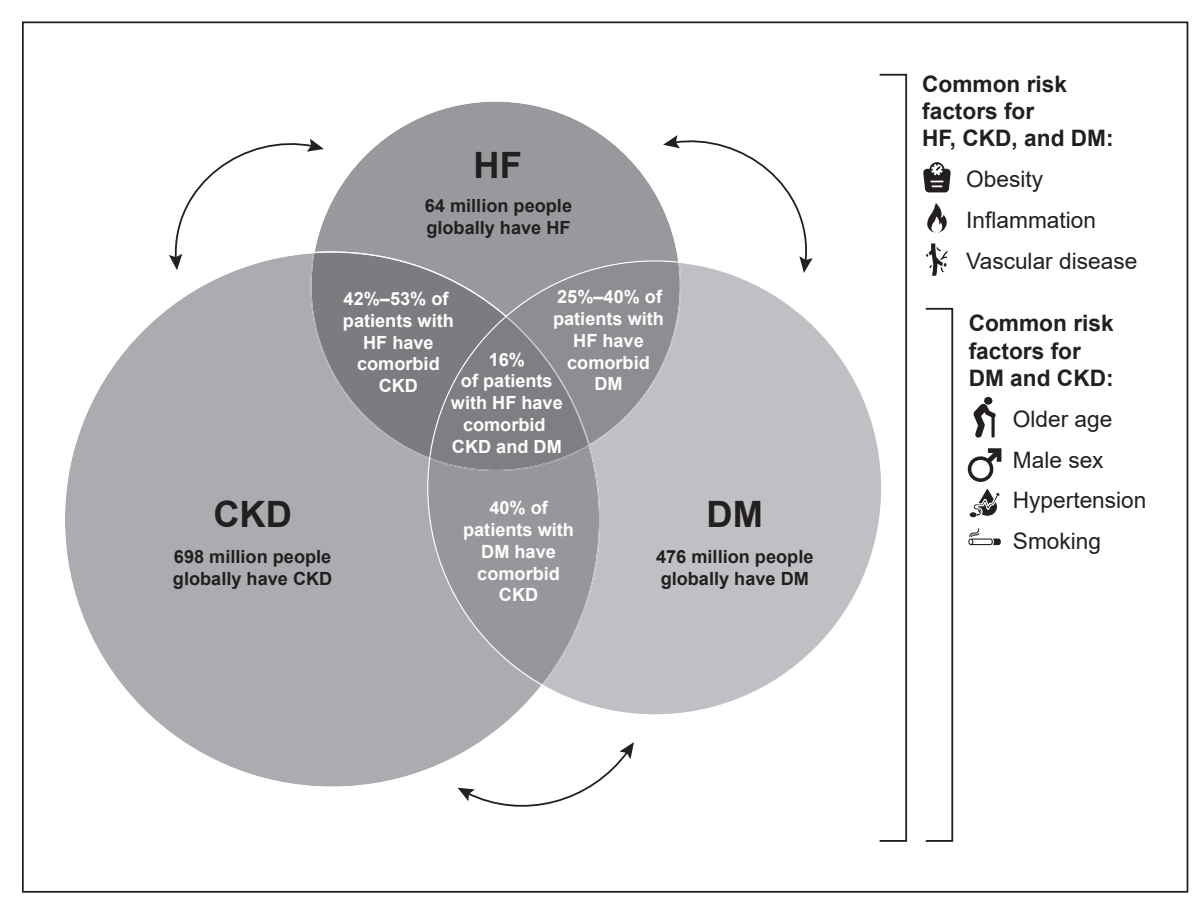

disease triad associated with worse clinical outcomes [5]. As the number of Americans living with HF is expected to increase by $46 \%$ between 2012 and 2030 [6], efforts are urgently needed to improve the treatment of patients with multimorbidities and HF. Issues and evidence relevant to the comanagement of $\mathrm{HF}, \mathrm{CKD}$, and DM are described herein.

\section{The Complex Interaction between HF, DM, and CKD}

\section{Interactions between $\mathrm{HF}$ and DM}

$\mathrm{DM}$ is associated with an increased risk of cardiovascular disease (CVD), cardiovascular (CV) mortality, and a more severe disease course. The likelihood of developing CVD is 1.5 -fold higher in patients with DM than in patients without DM, and the likelihood of experiencing $\mathrm{CV}$-related events (e.g., myocardial infarction or stroke) is higher in patients with severe or uncontrolled DM [6]. Furthermore, DM increases the risk of developing HF, with greater risk observed in women with DM than in men with DM [2]. The high prevalence of HF (Fig. 1) and increased risk of new-onset HF in individuals with DM compared to individuals in general or matched populations [2] support a shared pathogenesis between the 2 conditions.

DM can contribute to the development of both CVD and HF via cellular, molecular, and systemic mecha- nisms, which have been described extensively elsewhere [7]. In brief, DM is characterized by hyperglycemia and insulin resistance, which trigger a cascade of deleterious effects. In particular, these features can drive inflammation, dyslipidemia, endothelial dysfunction (leading to coronary artery disease, fibrosis, left ventricular [LV] hypertrophy, and cardiomyocyte dysfunction), and autonomic dysfunction (leading to systolic and diastolic dysfunction) [7]. Conversely, HF may be an independent risk factor for DM through mechanisms related to neurohormonal activation and chronic inflammation [8]. Metabolic risks may be further heightened by the use of glucose-lowering medication that can increase the risk of mortality and hospitalization in patients with or without HF [2].

\section{Interactions between $H F$ and $C K D$}

CKD may be a disease multiplier $[9,10]$, wherein as disease severity worsens (Fig. 2), the risks of CV events, hospitalization, and mortality increase [11]. For example, patients with stage 3 or 4 CKD or microalbuminuria are at higher risk of CV-related mortality than those with normal kidney function or normal albuminuria [11]. In addition, in the Atherosclerosis Risk in Communities study of nearly 15,000 individuals without HF, the presence of stage $\geq 3 \mathrm{CKD}$ (estimated glomerular filtration rate $[e G F R]<60 \mathrm{~mL} / \mathrm{min} / 1.73 \mathrm{~m}^{2}$ ) was independently associated with a 1.9-fold increased risk of incident HF 
Fig. 2. Prognosis of CKD by GFR and albuminuria category: Kidney Disease: Improving Global Outcomes (KDIGO) 2012 [11]. The colors represent low risk (green; i.e., if no other markers of kidney disease, no CKD), moderately increased risk (yellow), high risk (orange), and very high risk (red). Reproduced with permission from the KDIGO Work Group [11].

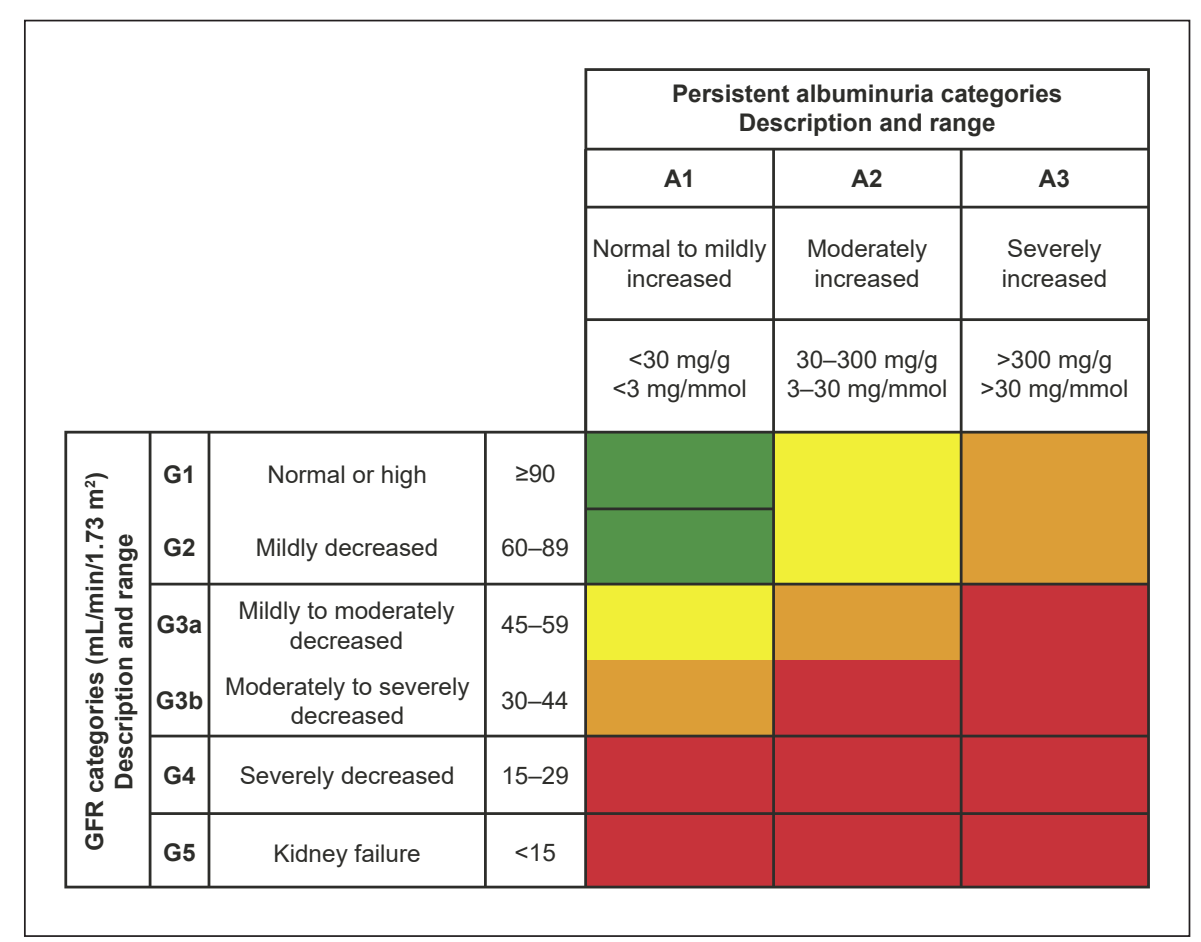

compared with the reference group, who all had an eGFR of $\geq 90 \mathrm{~mL} / \mathrm{min} / 1.73 \mathrm{~m}^{2}$ [9].

Complex, bidirectional mechanisms underpin the interaction between CKD and HF. Patients can experience impaired kidney function secondary to heart disease, heart disease secondary to impaired kidney function, or concurrent dysfunction of both organs, termed cardiorenal syndrome. In cardiorenal syndrome, acute or chronic failure of either organ can induce impairment of the other organ $[9,10]$. Systemic complications (e.g., DM) also contribute to renal and cardiac injury. Injuries to both organs can then drive inflammation, oxidative stress, hemodynamic changes, and neurohormonal activation (i.e., of the renin-angiotensin-aldosterone system [RAAS] and systemic nervous system). Independently, renal injury can also cause anemia, metabolic abnormalities, and volume overload leading to cardiac injury, while cardiac injury can cause hemodynamic changes leading to renal injury $[9,10]$.

In patients with cardiorenal syndrome, differentiating primary and secondary disease can be challenging because of these diseases' common risk factors and pathophysiology [9]. A multidisciplinary treatment approach is therefore needed to optimize care for patients with HF and CKD [9]. In particular, since anemia is common in CKD and can independently increase the risk of hospitalization and mortality in individuals with HF, clinical practice guidelines recommend the evaluation and treatment of iron deficiency anemia in this patient population [12].

\section{Interactions between $D M$ and $C K D$}

The link between DM and CKD, independent of HF, is beyond the scope of the current review. However, it is important to acknowledge that DM is the leading cause of CKD [4]. Moreover, patients with DM and CKD are at high risk for CVD, including HF [4]. In patients with DM, risk factors for CKD include older age, male sex, smoking, obesity, and hypertension [6]. Among these risk factors, obesity and hypertension can stimulate inflammatory, fibrotic, and hemodynamic changes (e.g., activation of the RAAS), resulting in high intraglomerular pressure as well as glomerular hyperfiltration with eventual progression to CKD [13].

\section{Outcomes of HF, DM, and CKD}

There is now increased research focus on the impact of comorbidities across the spectrum of HF $[14,15]$. In particular, DM and CKD are common comorbidities associated with both $\mathrm{HF}$ with reduced ejection fraction (HFrEF) (LV ejection fraction $[\mathrm{LVEF}] \leq 40 \%$ ) and HF with preserved ejection fraction (HFpEF) (LVEF >50\%) $[14,15]$. These comorbidities are thought to drive HFpEF development via systemic inflammation and its effects on cardiac 
function. By contrast, cardiac insult is thought to precede HFrEF, with later development of DM and CKD $[14,15]$. However, more research is needed to clarify the mechanisms that underlie the progression of DM and CKD to HFpEF versus those linking HFrEF to DM and CKD.

Regardless of the type of HF, the combined effect of HF, DM, and CKD leads to an increased risk of hospitalization and mortality in the patients who are impacted [5]. Real-world data from almost 90,000 individuals in the United Kingdom reported hospitalization and mortality rates during the first year after HF diagnosis in patients with HF $(n=21,815), \mathrm{HF}+\mathrm{CKD}(n=26,881), \mathrm{HF}+\mathrm{DM}$ $(n=7,893)$, and HF $+\mathrm{DM}+\mathrm{CKD}(n=10,638)$. CV-related hospitalization rates were highest in patients with all 3 conditions (89.1\%) compared to patients with HF only (35.1\%), HF + CKD (46.4\%), and HF + DM (49.2\%). Non-CV-related hospitalization rates were also highest among patients with all 3 conditions (223.2 events per 100 person-years [ppy]) compared to patients with other morbidities (HF only, 62.2 ppy; HF + CKD, 71.7 ppy; HF $+\mathrm{DM}, 85.1$ ppy). Last, mortality rates were $78.6 \%$ in patients with $\mathrm{HF}+\mathrm{CKD}+\mathrm{DM}, 20.5 \%$ in patients with $\mathrm{HF}$ only, $24.9 \%$ in patients with $\mathrm{HF}+\mathrm{CKD}$, and $25.1 \%$ in patients with $\mathrm{HF}+\mathrm{DM}[5]$.

\section{Case Study of Concomitant HF, DM, and CKD}

A 64-year-old woman, nonsmoker, with a 15-year history of DM, retinopathy that improved approximately $70 \%$ following laser surgery, home-recorded blood pressure approximately $140 / 90 \mathrm{~mm} \mathrm{Hg}$, and a stent implanted in her superficial femoral artery 5 months earlier, developed edema and dyspnea on exertion that appeared to respond to treatment with furosemide. An electrocardiogram showed sinus rhythm with nonspecific ST changes (heart rate, 78 beats per minute; QRS duration, $100 \mathrm{~ms}$ ). Left heart catheterization demonstrated nonocclusive 3 -vessel disease; LVEF was $36 \%$ by echocardiography. The patient's eGFR was $48 \mathrm{~mL} / \mathrm{min} / 1.73 \mathrm{~m}^{2}$, and spot urinary albumin:creatine ratio was $350 \mathrm{mg} / \mathrm{g}$. Other laboratory blood results showed glycated hemoglobin $7.6 \%$, eGFR $47 \mathrm{~mL} / \mathrm{min} / 1.73 \mathrm{~m}^{2}$, triglycerides $324 \mathrm{mg} / \mathrm{dL}$, lowdensity lipoprotein cholesterol $82 \mathrm{mg} / \mathrm{dL}$, hemoglobin $10.6 \mathrm{~g} / \mathrm{dL}$, brain natriuretic peptide $456 \mathrm{gg} / \mathrm{mL}$, and uric acid $16 \mathrm{mg} / \mathrm{dL}$. Potassium and sodium levels were normal. Medications concurrent with furosemide included atenolol, aspirin, clopidogrel, irbesartan, and metformin; lovastatin was stopped many years earlier because of joint pain that was attributed to taking the drug.
Challenges in the Management of This Case

This patient had multiple clinical features indicating high risk of CV events and progression of CKD. These clinical features included evidence of LV systolic dysfunction in conjunction with established peripheral artery disease, diabetic retinopathy, and CKD with severely increased albuminuria.

Because this patient had signs and symptoms of HFrEF, optimizing comprehensive disease-modifying medical therapy should be a priority. Management options are presented in the following sections and focus on newergeneration treatments for patients with HF; other treatment options for patients with DM or CKD alone are beyond the scope of this review article.

\section{Evidence in Management from Clinical Trials}

Angiotensin receptor-neprilysin inhibitor (ARNI), $\beta$-blockers, mineralocorticoid receptor antagonists (MRAs), and sodium-glucose cotransporter 2 (SGLT2) inhibitors are currently recommended as first-line medications in all patients with HFrEF [16]. ARNI is the preferred RAAS inhibitor compared to angiotensin-converting enzyme inhibitors (ACEis) or angiotensin II receptor blockers (ARBs) [16], based on evidence that sacubitril/ valsartan reduces the risk of hospitalization for HF and $\mathrm{CV}$-related mortality versus enalapril in patients with HFrEF [17]. In patients with newly diagnosed symptomatic HFrEF, an evidence-based $\beta$-blocker, with or without a diuretic, may be started at the same time as an ARNI. MRAs should also be added to the regimen; however, close monitoring of electrolytes and renal function is warranted [16]. Finally, SGLT2 inhibitors, in addition to foundational guideline-directed medical therapy, have been shown to reduce the risk of hospitalization and mortality in patients with HFrEF, regardless of the presence of DM [16]. To reduce the risk for atherosclerotic CVD, a statin can also be considered, alongside comprehensive lifestyle modifications. Taken together, our patient case study may benefit from replacing irbesartan with ARNI and metformin with an SGLT2 inhibitor.

As described above, there are multiple evidence-based treatment options for HFrEF. Recently, data have also emerged showing benefit of ARNI and SGLT2 inhibitors in some patients with HFpEF [18-20]. The PARADIGMHF trial demonstrated the superiority of sacubitril/valsartan $(n=4,187)$ versus enalapril $(n=4,212)$ in reducing $\mathrm{CV}$ death and first hospitalization for HF in patients with HFrEF $(p<0.001)$ [17]. The PIONEER-HF trial con- 


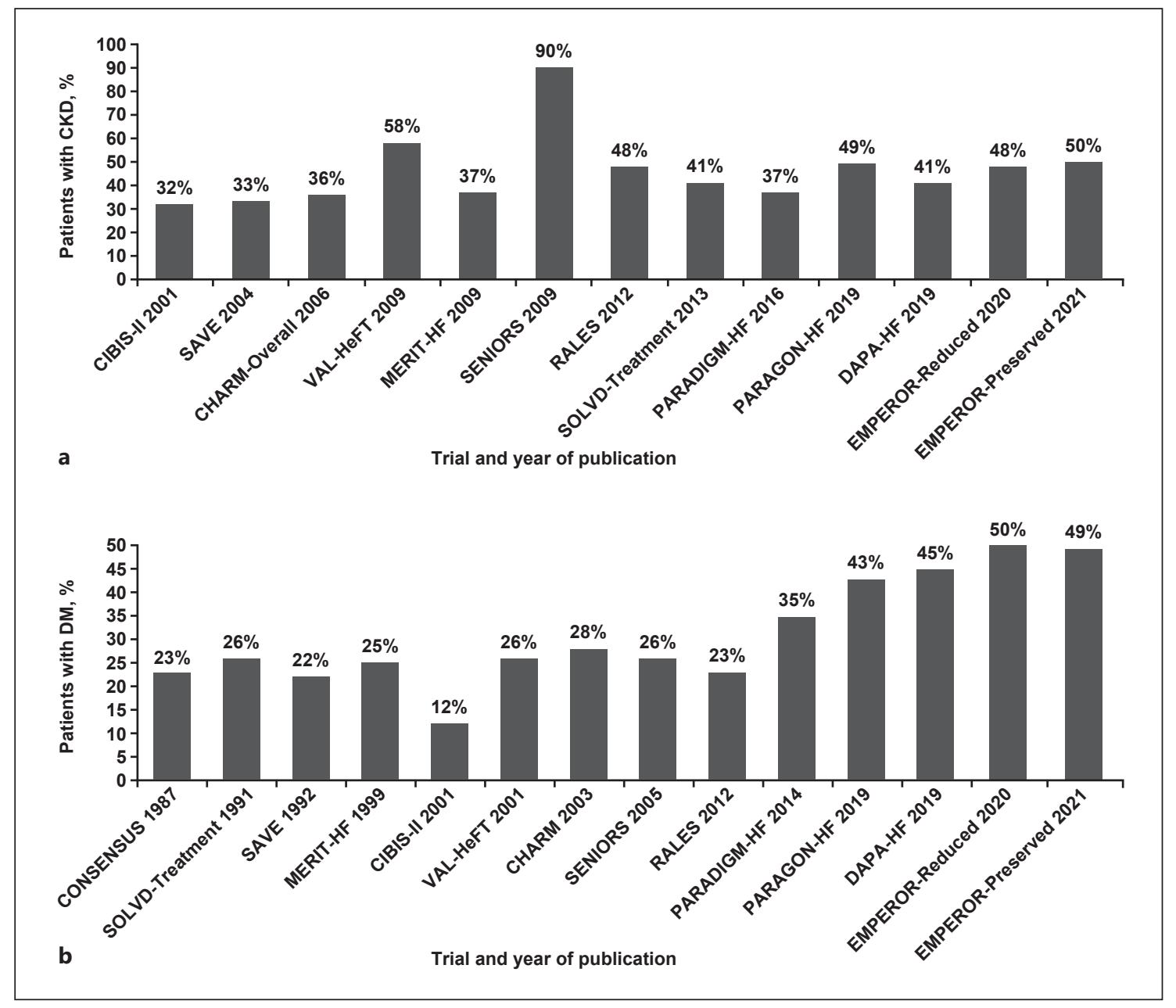

Fig. 3. Percentage of patients regardless of the treatment group who had CKD (a) and DM (b) in HF trials by the year of trial publication $[17,19,20,23,24,35-51]$.

firmed the safety of in-hospital initiation of sacubitril/valsartan following hemodynamic stabilization in patients with HFrEF [21]. In the PARAGON-HF trial $(n=4,822)$, fewer primary composite outcome events (CV death and hospitalizations for HF) were observed with sacubitril/ valsartan versus valsartan in patients with $\mathrm{HFpEF}$; however, the difference was not statistically significant $(p=$ 0.06) [19]. Subgroup analyses of PARAGON-HF showed potentially greater benefit of sacubitril/valsartan in female than in male patients, as well as in patients with LVEF $\leq 57 \%$ [19]. In February 2021, sacubitril/valsartan received approval for an expanded indication from the US Food and Drug Administration. The prescribing information now indicates that sacubitril/valsartan is approved to treat adults with chronic HF; benefits are most clearly evident in patients with below-normal LVEF, based on data from PARADIGM-HF and PARAGONHF [22]. The DAPA-HF $(n=4,744)$ and EMPEROR-Reduced $(n=3,730)$ trials demonstrated the superiority of dapagliflozin and empagliflozin versus placebo, respectively, in reducing events for the primary composite outcomes in patients with HFrEF (DAPA-HF: CV death and worsening HF; EMPEROR-Reduced: CV death and hospitalization for worsening HF; $p<0.001$ for both trials) $[23,24]$. In the EMPEROR-Preserved trial $(n=3,730)$, empagliflozin was superior to placebo in reducing the primary composite outcome of CV death and hospitalization for HF in patients with HFpEF, defined as LVEF $>40 \%(p<0.001)[20]$.

Renal benefits of ARNI have been shown in patients with HFrEF and HFpEF. Compared to an ACEi or ARB, ARNI is associated with smaller declines in eGFR in pa- 
Table 1. Recommended HF therapies and their use in CKD or DM

\begin{tabular}{|c|c|c|c|}
\hline $\begin{array}{l}\text { Recommended HF } \\
\text { therapy }[16,18]\end{array}$ & $\begin{array}{l}\text { Prevention of } \\
\text { mortality in CKD }\end{array}$ & $\begin{array}{l}\text { Prevention of } \\
\text { mortality in DM }\end{array}$ & Other considerations \\
\hline \multicolumn{4}{|l|}{ RAAS inhibitors } \\
\hline ACEi & Benefit [36] & Benefit [52] & $\begin{array}{l}\text { Risk of hypotension, angioedema, hyperkalemia, or elevated serum } \\
\text { creatinine, including in CKD }[17,36]\end{array}$ \\
\hline ARB & Possible benefit* [37] & Benefit* [38] & $\begin{array}{l}\text { Risk of hypotension, hyperkalemia, or elevated serum creatinine, } \\
\text { including in CKD }[37,38]\end{array}$ \\
\hline \multicolumn{4}{|c|}{ Evidence-based $\beta$-blockers, MRAs, and SGLT2 inhibitors } \\
\hline$\beta$-Blocker & Benefit [53] & Benefit [52] & $\begin{array}{l}\text { Risk of headache, orthostatic hypotension, hyperkalemia, and } \\
\text { hyperglycemia [53] }\end{array}$ \\
\hline MRA & Benefit* [54] & Benefit* [54] & Risk of hyperkalemia [54] \\
\hline SGLT2 inhibitor & Benefit $[34,55]$ & Benefit* $[23,28-31]$ & $\begin{array}{l}\text { Risk of diabetic ketoacidosis (rare in type } 2 \mathrm{DM} \text { ), genitourinary } \\
\text { infections, and volume depletion (multiple) }[23,28-30,56]\end{array}$ \\
\hline
\end{tabular}

* On a combined end point that included mortality and other morbid events.

tients with HFrEF and HFpEF and with reduced risk of renal events in patients with HFpEF $[25,26]$. Furthermore, based on a secondary analysis of PARADIGM-HF, ARNI also attenuates the rate of decline in eGFR among patients with comorbid HFrEF and DM [27]. Importantly, in individuals taking an RAAS inhibitor (e.g., ARNI, ACEi, ARB, or MRA), hyperkalemia is a concern, especially among those with impaired kidney function [16]. Although potassium-binding agents, such as patiromer, have been approved by the US Food and Drug Administration, more data are needed to support their use in patients with HF [16].

The newer generation of glucose-lowering drugs has also been shown to exert protective effects of varying magnitude on both the heart and the kidneys. In particular, the CV benefits of SGLT2 inhibitors [28-31] and glucagon-like peptide 1 receptor agonists $[32,33]$ have been shown in patients with DM, and the renal benefits of SGLT2 inhibitors have been shown in patients with CKD [34].

HF trials have largely excluded patients with advanced $\mathrm{CKD}$; therefore, most evidence is based on the experience of patients with moderate CKD (i.e., stage 3), who are reasonably well represented in randomized controlled trials. Figure $3 \mathrm{a}$ shows the percentage of patients in HF studies who also had CKD. Given that DM is a common comorbidity in these patients, Figure $3 \mathrm{~b}$ shows the percentage of patients in HF studies who also had DM.

Table 1 provides an overview of recommended therapies for HF and evidence for their effect in patients with CKD and/or DM. In general, treatment effects (e.g., on hospitalization and mortality) have been consistent in patients with HF, regardless of comorbid CKD or DM (Table 1). A systematic review and meta-analysis of randomized controlled trials in patients with HF found that treatment with ARNI resulted in a lower risk of renal dysfunction than other RAAS inhibitors [57]. This effect of ARNI in slowing eGFR deterioration has been attributed to the additive effect of increased natriuretic peptides caused by neprilysin inhibition compared with ACEi [57].

In the past decade, almost 20 trials of different glucoselowering agents have provided evidence on the $\mathrm{CV}$ and kidney effects of newer-generation drugs for DM. As a result, specific glucose-lowering agents are now recommended for the prevention of $\mathrm{CV}$ events and reduction of eGFR in individuals with DM. Table 2 details some of the more common glucose-lowering agents available. Broadly, dipeptidyl peptidase- 4 inhibitors are neutral for atherosclerotic CVD [61-64] and HF [61, 64, 65] except for saxagliptin, which showed an increased risk of hospitalization for HF [63]. SGLT2 inhibitors [28-31] and glucagon-like peptide 1 receptor agonists $[32,33,60,66,67]$ have also been shown to reduce the risk of $\mathrm{CV}$ and renal outcomes.

\section{Conclusion}

HF, DM, and CKD are complex, interlinked conditions. Treatment plans for patients with a combination of these comorbidities should consider the available clinical evidence while acknowledging that data are mainly limited to subgroup analyses of randomized controlled trials. 


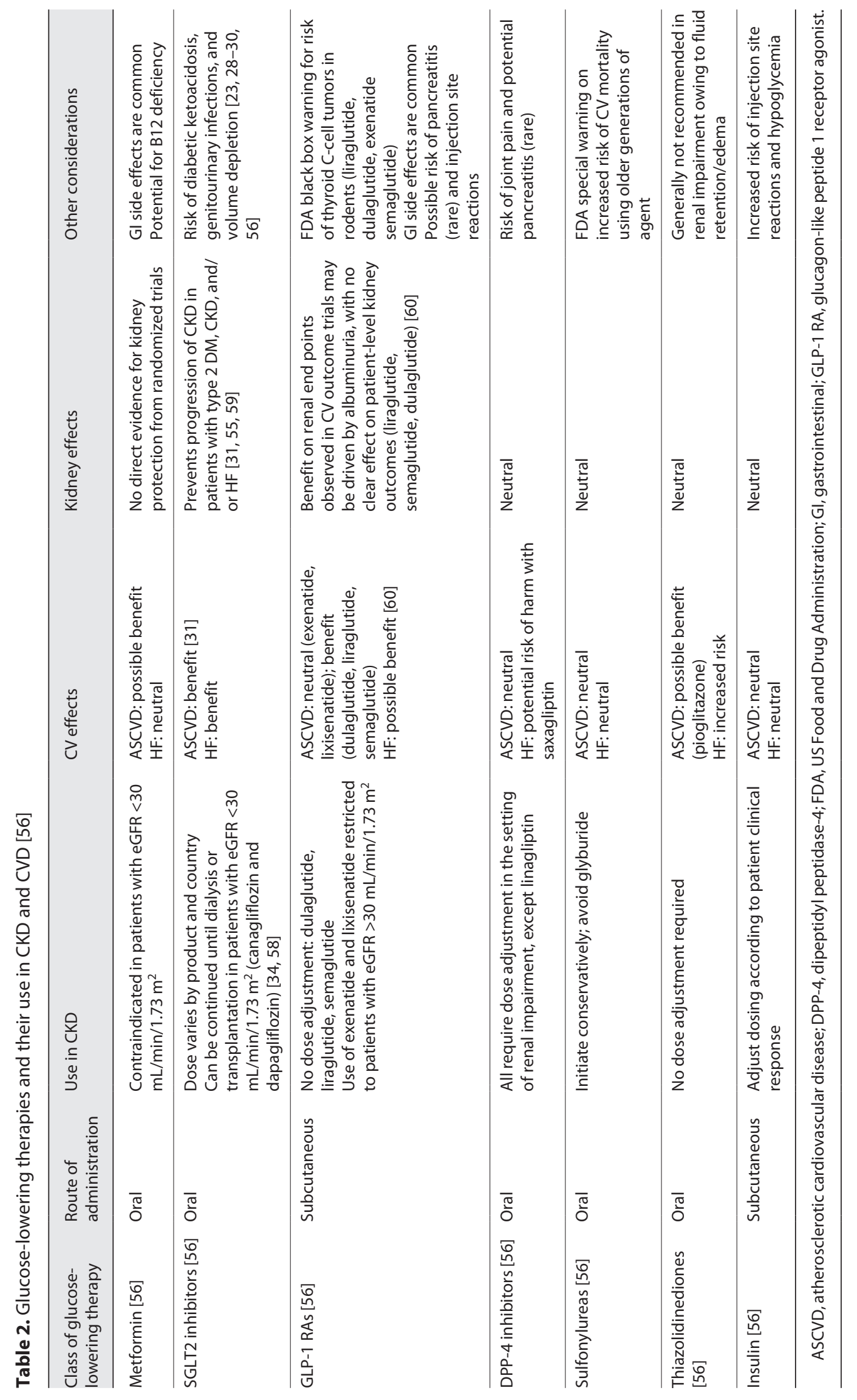

Heart Failure, Diabetes, and Chronic Kidney Disease 


\section{Acknowledgments}

Medical writing and editing support were provided by Julia Burke, PhD, and Traci Stuve MA of ApotheCom (Yardley, PA, USA), as well as Brittany Y. Jarrett, PhD, of Complete HealthVizion, McCann Health Medical Communications (Chicago, IL, USA). This support was funded by Novartis Pharmaceuticals Corporation.

\section{Statement of Ethics}

This article does not contain any studies with human participants or animals performed by any of the authors.

\section{Conflict of Interest Statement}

Financial arrangements of the authors with companies whose products may be related to the present report are listed below, as declared by the authors: Kris Vijay has served as a consultant, speaker, and/or advisor for Amarin Corporation, Amgen, Astra-
Zeneca, Aventyn, Baxter International, Boehringer Ingelheim/Eli Lilly and Company, Esperion Therapeutics, Legacy Heart Care, Novo Nordisk, and Pfizer. He is a board member of the Cardiorenal Society of America, Life 365, and the National Lipid Association. Brendon L. Neuen has received fees for advisory boards, steering committee roles, scientific presentations, and travel from AstraZeneca, Bayer AG, and Janssen Pharmaceuticals, with all honoraria paid to his employer. Edgar Lerma has no conflicts to declare.

\section{Funding Sources}

Novartis Pharmaceuticals Corporation provided funding for medical writing assistance.

\section{Author Contributions}

All authors made substantial contributions to the design and drafting of this review. All authors approved the final version for publication.

\section{References}

1 GBD 2017 Disease and Injury Incidence and Prevalence Collaborators. Global, regional, and national incidence, prevalence, and years lived with disability for 354 diseases and injuries for 195 countries and territories, 19902017: a systematic analysis for the Global Burden of Disease Study 2017. Lancet. 2018 Nov 10;392(10159):1789-858.

2 Rosano GM, Vitale C, Seferovic P. Heart failure in patients with diabetes mellitus. Card Fail Rev. 2017 Apr;3(1):52-5.

3 Damman K, Tang WH, Felker GM, Lassus J, Zannad F, Krum H, et al. Current evidence on treatment of patients with chronic systolic heart failure and renal insufficiency: practical considerations from published data. J Am Coll Cardiol. 2014 Mar 11;63(9):853-71.

4 Perkovic V, Agarwal R, Fioretto P, Hemmelgarn BR, Levin A, Thomas MC, et al. Management of patients with diabetes and CKD: conclusions from a "Kidney Disease: Improving Global Outcomes" (KDIGO) Controversies Conference. Kidney Int. 2016 Dec;90(6): 1175-83.

5 Lawson CA, Seidu S, Zaccardi F, McCann G, Kadam UT, Davies MJ, et al. Outcome trends in people with heart failure, type 2 diabetes mellitus and chronic kidney disease in the UK over twenty years. EClinicalMedicine. 2021 Feb;32:100739.

6 Virani SS, Alonso A, Aparicio HJ, Benjamin EJ, Bittencourt MS, Callaway CW, et al. Heart disease and stroke statistics-2021 update: a report from the American Heart Association. Circulation. 2021 Feb 23;143(8):e254-743.
7 Marwick TH, Ritchie R, Shaw JE, Kaye D. Implications of underlying mechanisms for the recognition and management of diabetic cardiomyopathy. J Am Coll Cardiol. 2018 Jan 23; 71(3):339-51.

8 Guglin M, Lynch K, Krischer J. Heart failure as a risk factor for diabetes mellitus. Cardiology. 2014;129(2):84-92.

9 House AA. Management of heart failure in advancing CKD: Core Curriculum 2018. Am J Kidney Dis. 2018 Aug;72(2):284-95.

10 Damman K, Testani JM. The kidney in heart failure: an update. Eur Heart J. 2015 Jun 14; 36(23):1437-44.

11 Kidney Disease: Improving Global Outcomes (KDIGO) CKD Work Group. KDIGO 2012 clinical practice guideline for the evaluation and management of chronic kidney disease. Kidney Int Suppl. 2013;3(1):134-5.

12 Beladan CC, Botezatu SB. Anemia and management of heart failure patients. Heart Fail Clin. 2021 Apr;17(2):195-206.

13 Alicic RZ, Rooney MT, Tuttle KR. Diabetic kidney disease: challenges, progress, and possibilities. Clin J Am Soc Nephrol. 2017 Dec 7; 12(12):2032-45.

14 van de Wouw J, Broekhuizen M, Sorop O, Joles JA, Verhaar MC, Duncker DJ, et al. Chronic kidney disease as a risk factor for heart failure with preserved ejection fraction: a focus on microcirculatory factors and therapeutic targets. Front Physiol. 2019;10:1108.
15 Simmonds SJ, Cuijpers I, Heymans S, Jones EAV. Cellular and molecular differences between HFpEF and HFrEF: a step ahead in an improved pathological understanding. Cells. 2020 Jan 18;9(1):242

16 Maddox TM, Januzzi JLJ, Allen LA, Breathett K, Butler J, Davis LL, et al. 2021 update to the 2017 ACC expert consensus decision pathway for optimization of heart failure treatment: answers to 10 pivotal issues about heart failure with reduced ejection fraction: a report of the American College of Cardiology Solution Set Oversight Committee. J Am Coll Cardiol. 2021 Feb;77(6):772-810.

17 McMurray JJV, Packer M, Desai AS, Gong J, Lefkowitz MP, Rizkala AR, et al. Angiotensinneprilysin inhibition versus enalapril in heart failure. N Engl J Med. 2014 Sep;371(11):9931004.

18 Yancy CW, Jessup M, Bozkurt B, Butler J, Casey DE Jr, Drazner MH, et al. 2013 ACCF/AHA guideline for the management of heart failure: a report of the American College of Cardiology Foundation/American Heart Association Task Force on Practice Guidelines. J Am Coll Cardiol. 2013 Oct 15;62(16):e147-239.

19 Solomon SD, McMurray JJV, Anand IS, Ge J, Lam CSP, Maggioni AP, et al. Angiotensinneprilysin inhibition in heart failure with preserved ejection fraction. N Engl J Med. 2019 Sep;381(17):1609-20.

20 Anker SD, Butler J, Filippatos G, Ferreira JP, Bocchi E, Bohm M, et al. Empagliflozin in heart failure with a preserved ejection fraction. N Engl J Med. 2021 Aug 27;385(16): 1451-61. 
21 Velazquez EJ, Morrow DA, DeVore AD, Duffy CI, Ambrosy AP, McCague K, et al. Angiotensin-neprilysin inhibition in acute decompensated heart failure. N Engl J Med. 2019 Feb;380(6):539-48.

22 Novartis. ENTRESTO prescribing information. 20212021 Apr 28. Available from: https: //www.novartis.us/sites/www.novartis.us/ files/entresto.pdf.

23 McMurray JJV, Solomon SD, Inzucchi SE, Køber L, Kosiborod MN, Martinez FA, et al. Dapagliflozin in patients with heart failure and reduced ejection fraction. N Engl J Med. 2019 Sep;381(21):1995-2008.

24 Packer M, Anker SD, Butler J, Filippatos G, Pocock SJ, Carson P, et al. Cardiovascular and renal outcomes with empagliflozin in heart failure. N Engl J Med. 2020 Aug;383:1413-24.

25 Damman K, Gori M, Claggett B, Jhund PS, Senni M, Lefkowitz MP, et al. Renal effects and associated outcomes during angiotensinneprilysin inhibition in heart failure. JACC Heart Fail. 2018 Jun;6(6):489-98.

26 Mc Causland FR, Lefkowitz MP, Claggett B, Anavekar NS, Senni M, Gori M, et al. Angiotensin-neprilysin inhibition and renal outcomes in heart failure with preserved ejection fraction. Circulation. 2020 Sep 29;142(13): 1236-45.

27 Packer M, Claggett B, Lefkowitz MP, McMurray JJV, Rouleau JL, Solomon SD, et al. Effect of neprilysin inhibition on renal function in patients with type 2 diabetes and chronic heart failure who are receiving target doses of inhibitors of the renin-angiotensin system: a secondary analysis of the PARADIGM-HF trial. Lancet Diabetes Endocrinol. 2018 Jul; 6(7):547-54.

28 Wiviott SD, Raz I, Bonaca MP, Mosenzon O, Kato ET, Cahn A, et al. Dapagliflozin and cardiovascular outcomes in type 2 diabetes. $\mathrm{N}$ Engl J Med. 2019 Jan 24;380(4):347-57.

29 Neal B, Perkovic V, Mahaffey KW, de Zeeuw D, Fulcher G, Erondu N, et al. Canagliflozin and cardiovascular and renal events in type 2 diabetes. N Engl J Med. 2017 Aug;377(7):644-57.

30 Zinman B, Wanner C, Lachin JM, Fitchett D, Bluhmki E, Hantel S, et al. Empagliflozin, cardiovascular outcomes, and mortality in type 2 diabetes. N Engl J Med. 2015 Nov 26;373(22): 2117-28.

31 McGuire DK, Shih WJ, Cosentino F, Charbonnel B, Cherney DZI, Dagogo-Jack S, et al. Association of SGLT2 inhibitors with cardiovascular and kidney outcomes in patients with type 2 diabetes: a meta-analysis. JAMA Cardiol. 2021 Feb 1;6(2):148-58.

32 Marso SP, Bain SC, Consoli A, Eliaschewitz FG, Jódar E, Leiter LA, et al. Semaglutide and cardiovascular outcomes in patients with type 2 diabetes. N Engl J Med. 2016 Nov 10; 375(19):1834-44.

33 Marso SP, Daniels GH, Brown-Frandsen K, Kristensen P, Mann JF, Nauck MA, et al. Liraglutide and cardiovascular outcomes in type 2 diabetes. N Engl J Med. 2016 Jul 28; 375(4):311-22.
34 Heerspink HJL, Stefansson BV, Correa-Rotter R, Chertow GM, Greene T, Hou FF, et al. Dapagliflozin in patients with chronic kidney disease. N Engl J Med. 2020 Oct 8;383(15): 1436-46.

35 Kristensen SL, Preiss D, Jhund PS, Squire I, Cardoso JS, Merkely B, et al. Risk related to pre-diabetes mellitus and diabetes mellitus in heart failure with reduced ejection fraction: Insights from prospective comparison of ARNI with ACEI to determine impact on global mortality and morbidity in heart failure trial. Circ Heart Fail. 2016 Jan;9(1): e002560.

36 Bowling CB, Sanders PW, Allman RM, Rogers WJ, Patel K, Aban IB, et al. Effects of enalapril in systolic heart failure patients with and without chronic kidney disease: insights from the SOLVD Treatment trial. Int J Cardiol. 2013 Jul 15;167(1):151-6.

37 Anand IS, Bishu K, Rector TS, Ishani A, Kuskowski MA, Cohn JN. Proteinuria, chronic kidney disease, and the effect of an angiotensin receptor blocker in addition to an angiotensin-converting enzyme inhibitor in patients with moderate to severe heart failure. Circulation. 2009 Oct 20;120(16):1577-84.

38 Cohn JN, Tognoni G; Valsartan Heart Failure Trial Investigators. A randomized trial of the angiotensin-receptor blocker valsartan in chronic heart failure. N Engl J Med. 2001 Dec 6;345(23):1667-75.

39 Tokmakova MP, Skali H, Kenchaiah S, Braunwald E, Rouleau JL, Packer M, et al. Chronic kidney disease, cardiovascular risk, and response to angiotensin-converting enzyme inhibition after myocardial infarction: the Survival And Ventricular Enlargement (SAVE) study. Circulation. 2004 Dec 14; 110(24):3667-73.

40 Erdmann E, Lechat P, Verkenne P, Wiemann $\mathrm{H}$. Results from post-hoc analyses of the CIBIS II trial: effect of bisoprolol in high-risk patient groups with chronic heart failure. Eur J Heart Fail. 2001 Aug;3(4):469-79.

41 Vardeny O, Wu DH, Desai A, Rossignol P, Zannad F, Pitt B, et al. Influence of baseline and worsening renal function on efficacy of spironolactone in patients with severe heart failure: insights from RALES (Randomized Aldactone Evaluation Study). J Am Coll Cardiol. 2012 Nov 13;60(20):2082-9.

42 Ghali JK, Wikstrand J, Van Veldhuisen DJ, Fagerberg B, Goldstein S, Hjalmarson A, et al. The influence of renal function on clinical outcome and response to beta-blockade in systolic heart failure: insights from Metoprolol CR/XL Randomized Intervention Trial in Chronic HF (MERIT-HF). J Card Fail. 2009 May;15(4):310-8.

43 Hillege HL, Nitsch D, Pfeffer MA, Swedberg K, McMurray JJV, Yusuf S, et al. Renal function as a predictor of outcome in a broad spectrum of patients with heart failure. Circulation. 2006 Feb 7;113(5):671-8.

44 Cohen-Solal A, Kotecha D, van Veldhuisen DJ, Babalis D, Böhm M, Coats AJ, et al. Effi- cacy and safety of nebivolol in elderly heart failure patients with impaired renal function: insights from the SENIORS trial. Eur J Heart Fail. 2009 Sep;11(9):872-80.

45 Shah AM, Cikes M, Prasad N, Li G, Getchevski S, Claggett B, et al. Echocardiographic features of patients with heart failure and preserved left ventricular ejection fraction. J Am Coll Cardiol. 2019 Dec;74(23):2858-73.

46 MERIT-HF Study Group. Effect of metoprolol CR/XL in chronic heart failure: Metoprolol CR/XL Randomised Intervention Trial in Congestive Heart Failure (MERIT-HF). Lancet. 1999 Jun 12;353(9169):2001-7.

47 The SOLVD Investigators; Yusuf S, Pitt B, Davis CE, Hood WB, Cohn JN. Effect of enalapril on survival in patients with reduced left ventricular ejection fractions and congestive heart failure. N Engl J Med. 1991 Aug;325(5):293-302.

48 Pfeffer MA, Swedberg K, Granger CB, Held P, McMurray JJV, Michelson EL, et al. Effects of candesartan on mortality and morbidity in patients with chronic heart failure: the CHARM-Overall programme. Lancet. 2003 Sep 6;362(9386):759-66.

49 Flather MD, Shibata MC, Coats AJ, Van Veldhuisen DJ, Parkhomenko A, Borbola J, et al. Randomized trial to determine the effect of nebivolol on mortality and cardiovascular hospital admission in elderly patients with heart failure (SENIORS). Eur Heart J. 2005 Feb;26(3):215-25.

50 Consensus Trial Study Group. Effects of enalapril on mortality in severe congestive heart failure. Results of the Cooperative North Scandinavian Enalapril Survival Study (CONSENSUS). N Engl J Med. 1987 Jun 4;316(23):1429-35.

51 Pfeffer MA, Braunwald E, Moyé LA, Basta L, Brown EJJ, Cuddy TE, et al. Effect of captopril on mortality and morbidity in patients with left ventricular dysfunction after myocardial infarction: results of the survival and ventricular enlargement trial. N Engl J Med. 1992 Sep 3;327(10):669-77.

52 Shekelle PG, Rich MW, Morton SC, Atkinson CSW, Tu W, Maglione M, et al. Efficacy of angiotensin-converting enzyme inhibitors and beta-blockers in the management of left ventricular systolic dysfunction according to race, gender, and diabetic status: a meta-analysis of major clinical trials. J Am Coll Cardiol. 2003 May;41(9):1529-38.

53 Wali RK, Iyengar M, Beck GJ, Chartyan DM, Chonchol M, Lukas MA, et al. Efficacy and safety of carvedilol in treatment of heart failure with chronic kidney disease: a meta-analysis of randomized trials. Circ Heart Fail. 2011 Jan;4(1):18-26.

54 Eschalier R, McMurray JJ, Swedberg K, van Veldhuisen DJ, Krum H, Pocock SJ, et al. Safety and efficacy of eplerenone in patients at high risk for hyperkalemia and/or worsening renal function: analyses of the EMPHASISHF study subgroups (Eplerenone in Mild Patients Hospitalization And SurvIval Study in Heart Failure). J Am Coll Cardiol. 2013 Oct; 62(17):1585-93.
Heart Failure, Diabetes, and Chronic Kidney Disease
Cardiorenal Med 2022;12:1-10 DOI: $10.1159 / 000520909$ 
55 Perkovic V, Jardine MJ, Neal B, Bompoint S, Heerspink HJL, Charytan DM, et al. Canagliflozin and renal outcomes in type 2 diabetes and nephropathy. N Engl J Med. 2019 Jun 13; 380(24):2295-306.

56 American Diabetes Association. 9. Pharmacologic approaches to glycemic treatment: standards of medical care in diabetes-2021. Diabetes Care. 2021 Jan;44(Suppl 1):S111-24.

57 Spannella F, Giulietti F, Filipponi A, Sarzani R. Effect of sacubitril/valsartan on renal function: a systematic review and meta-analysis of randomized controlled trials. ESC Heart Fail. 2020 Sep 22;7(6):3487-96.

58 Neuen BL, Jardine MJ, Perkovic V. Sodiumglucose cotransporter 2 inhibition: which patient with chronic kidney disease should be treated in the future? Nephrol Dial Transplant. 2020 Jan 1;35(Suppl 1):i48-55.

59 Tuttle KR, Brosius FC III, Cavender MA, Fioretto $\mathrm{P}$, Fowler KJ, Heerspink HJL, et al. SGLT2 inhibition for CKD and cardiovascular disease in type 2 diabetes: report of a scientific workshop sponsored by the National Kidney Foundation. Am J Kidney Dis. 2021 Jan;77(1):94-109.
60 Sattar N, Lee MMY, Kristensen SL, Branch KRH, Del Prato S, Khurmi NS, et al. Cardiovascular, mortality, and kidney outcomes with GLP-1 receptor agonists in patients with type 2 diabetes: a systematic review and metaanalysis of randomised trials. Lancet Diabetes Endocrinol. 2021 Oct;9(10):653-62.

61 Green JB, Bethel MA, Armstrong PW, Buse JB, Engel SS, Garg J, et al. Effect of sitagliptin on cardiovascular outcomes in type 2 diabetes. N Engl J Med. 2015 Jul 16;373(3):232-42.

62 White WB, Cannon CP, Heller SR, Nissen SE, Bergenstal RM, Bakris GL, et al. Alogliptin after acute coronary syndrome in patients with type 2 diabetes. N Engl J Med. 2013 Oct 3; 369(14):1327-35.

63 Scirica BM, Bhatt DL, Braunwald E, Steg PG, Davidson J, Hirshberg B, et al. Saxagliptin and cardiovascular outcomes in patients with type 2 diabetes mellitus. N Engl J Med. 2013 Oct; 369(14):1317-26
64 Rosenstock J, Perkovic V, Johansen OE, Cooper ME, Kahn SE, Marx N, et al. Effect of linagliptin vs placebo on major cardiovascular events in adults with type 2 diabetes and high cardiovascular and renal risk: the CARMELINA randomized clinical trial. JAMA. 2019; 321(1):69-79.

65 Zannad F, Cannon CP, Cushman WC, Bakris GL, Menon V, Perez AT, et al. Heart failure and mortality outcomes in patients with type 2 diabetes taking alogliptin versus placebo in EXAMINE: a multicentre, randomised, double-blind trial. Lancet. 2015 May 23; 385(9982):2067-76.

66 Gerstein HC, Colhoun HM, Dagenais GR, Diaz R, Lakshmanan M, Pais P, et al. Dulaglutide and cardiovascular outcomes in type 2 diabetes (REWIND): a double-blind, randomised placebo-controlled trial. Lancet. 2019 Jul 13;394(10193):121-30.

67 Hernandez AF, Green JB, Janmohamed S, D'Agostino RB Sr., Granger CB, Jones NP, et al. Albiglutide and cardiovascular outcomes in patients with type 2 diabetes and cardiovascular disease (Harmony Outcomes): a double-blind, randomised placebo-controlled trial. Lancet. 2018 Oct 27;392(10157):1519-29. 